

\title{
ANÁLISE DA GESTÃO LOGÍSTICA E DOS RELACIONAMENTOS ENTRE FRIGORÍFICO E FORNECEDOR DO GADO DE CORTE
}

\author{
ANALYSIS OF LOGISTICS MANAGEMENT AND OF RELATIONSHIPS BETWEEN \\ FRIDGE AND OF BEEF CATTLE SUPPLIER
}

\author{
Bruna Moura Beck ${ }^{1}$ \\ iD Deoclécio Junior Cardoso da Silva² \\ iD Rafael Fasolo ${ }^{3}$ \\ iD Natália Pedroso Serpa ${ }^{4}$ \\ D Angelica Alebrant Mendes 5
}

\author{
${ }^{1}$ Bacharela em Administração \\ Universidade Regional Integrada do Alto Uruguai e \\ das Missões Campus Santo Ângelo - URI Santo \\ Ângelo \\ mbruna.corp@gmail.com \\ 2 Mestre em Engenharia de Produção \\ Universidade Federal de Santa Maria - UFSM \\ deocleciojunior2009@hotmail.com \\ ${ }^{3}$ Mestre em Administração \\ Universidade Regional Integrada do Alto Uruguai e \\ das Missões Campus Santo Ângelo - URI Santo \\ Ângelo \\ rfascex@hotmail.com \\ ${ }^{3}$ Mestre em Engenharia de Produção \\ Universidade Federal de Santa Maria - UFSM \\ nataliapedrososerpa@gmail.com \\ ${ }^{3}$ Doutora em Engenharia de Produção \\ Universidade Federal do ABC- UFABC \\ angelica.mendes@ufsm.br
}

Recebido em: 11 mar. 2019

Aprovado em: 13 fev. 2020
Resumo: Diante da importância da gestão logística nos tempos atuais, bem como a integração entre todos os participantes desta, torna-se vital as organizações buscarem aperfeiçoamento nessa temática. Desse modo, o presente estudo fora desenvolvido em um frigorífico localizado na região noroeste do estado do Rio Grande do Sul com o objetivo de investigar a integração entre frigorífico e fornecedor, além de realizar uma análise da gestão logística, identificando os gargalos existentes e apresentando sugestões de melhorias. O trabalho se desenvolveu através de uma pesquisa bibliográfica, seguida por uma coleta de dados a campo, onde se realizaram entrevistas junto aos pesquisados e, por fim, realizouse o tratamento dos dados através do software Microsoft Excel. Diante desses resultados realizou-se uma análise de toda a gestão da cadeia logística da carne bovina, auxiliando na verificação de pontos críticos e na existência de possíveis sugestões de melhorias.

Palavras-chave: Gestão logística. Cadeia produtiva de bovino de corte. Processo de integração.

Abstract: Given the importance of logistics management in the current times, as well as the integration between all participants of this list, it becomes vital as the search activities improved in this theme. In this way, the present study was developed in a refrigerator located in the northwest region of Rio Grande do Sul state with the objective of investigating an integration between refrigerator and supplier, besides performing a logistics management analysis, identifying the existing bottlenecks and the following improvement strategies. The work is carried out through a bibliographic research, followed by data collection in the field, where interviews with researchers are performed and, finally, performed or treated with data through Microsoft Excel software. Given these results, an analysis of the entire management of the beef logistics chain is performed, assisting in the verification of critical points and in the probability of possible suggestions for improvements.

Keywords: Logistics management. Production chain of beef cattle. Integration process. 


\section{Introdução}

A preocupação com a gestão correta da cadeia de suprimentos tem norteado o setor do gado de corte para um viés diferenciado, exigindo das organizações diferentes formas de gerenciamento e cuidado desde o produtor/fornecedor até o consumidor final (Holweg, 2005).

Assim, entende-se que com a gestão correta da cadeia de suprimentos, é possível integrar e sincronizar as atividades desenvolvidas pelas organizações, realizando uma execução conjunta entre as empresas envolvidas no processo respondendo ao cliente em menor tempo e com maior qualidade (Corrêa, 2014).

Quando se fala em Supply Chain Management (SCM) ou gestão da cadeia de suprimentos, verifica-se a existência de duas perspectivas de valor, a de tradicional e a de mercado, pois, este último é regulado pela lei de oferta e de procura. Ademais, além de se considerar o valor real, deve-se também observar o quanto o mercado está pagando por determinado bem de consumo.

Além disso, entende-se que a cadeia de suprimentos é uma rede de empresas que interagem entre si de forma autônoma, operando de forma conjunta com outros fluxos que integram o sistema logístico (Bonamigo \& Rodriguez, 2017). Diante dessa prerrogativa, alinhando ao objetivo da presente pesquisa, Formigoni (2017) afirma que a carne bovina é uma das carnes mais consumidas no mundo, estimando-se que seja de 7,90 kg/ano por habitante, sendo que no Brasil este consumo chega a quase $36 \mathrm{~kg}$ por pessoa. Segundo a Food and Agriculture Organization of the United Nations (FAO) (2017), até 2050 a demanda global de produtos pecuários irá aumentar em cerca de 70\%, o que demonstra que o setor do gado de corte tem um grande potencial de crescimento e o desafio de proporcionar produtos de qualidade.

Diante ao elucidado, torna-se imprescindível que uma organização considere a avaliação, monitoramento e controle de sua cadeia de suprimentos pois, realizando essas etapas com sucesso, a empresa conseguirá obter uma maior confiabilidade perante seus consumidores. Além disso, por se tratar de uma empresa do setor alimentício, é importante que as empresas fidelizem seus clientes através de produtos de qualidade. Assim, denota-se a relevância do presente estudo, pois o mesmo buscou como foco principal contribuir com melhorias para a integração entre o frigorífico e fornecedores, tendo por objetivos secundários identificar os gargalos e propor sugestões de melhoria.

\section{Referencial teórico}

\subsection{Gestão logística do gado de corte e perdas ocorridas na linha produtiva}

Para o Council of Supply Chain Management Professionals [CSCMP] (2013), a logística pode ser definida como a parte operacional da cadeia de suprimentos compreendendo desde o planejamento, implementação e controle do fluxo direto e reverso, armazenagem de produtos, bem como os serviços 
e informações associados, cobrindo desde o ponto de origem até o de consumo, com foco em atender aos requisitos do consumidor, e o SCM, como um conceito que complementa o primeiro, porém, mais amplo, abrangendo não só atividades operacionais e gerenciais, bem como, a questão comportamental, ou seja, a coordenação, integração de relacionamentos e as práticas colaborativas realizadas entre os diferentes integrantes da cadeia de suprimentos.

Além disso, diversas pesquisas foram realizadas acerca da gestão logística do gado de corte e as perdas ocorridas na linha de produção, como o trabalho realizado por Knoll et al. (2017).

Diante disso, é evidente a importância de o gestor ter pleno controle acerca da proveniência da matéria-prima até a qualidade de seu produto final, a fim de que se evitem perdas antes, durante e após o processo produtivo. No que tange à busca pela melhoria dos produtos, diversos estudos desenvolvidos acerca da saúde dos animais que serão abatidos (Diskin \& Kenny, 2016), bem como sobre o transporte correto tem tomado espaço, com o intuito de reduzir perdas tanto monetárias, quanto de matéria-prima, contribuindo cada vez mais com o desenvolvimento de práticas que garantam qualidade em todos os aspectos. Ademais, outro fator importante abordado em estudos logísticos em frigoríficos é a questão ambiental, onde diversos autores preocuparam-se com o quesito das emissões de gases, a qualidade e a segurança dos alimentos produzidos nessas organizações (Jordan et al., 2009; Mirandade la Lama, 2010; Soysal; Bloemhof-Ruwaard; Van der Vorst, 2014; Miranda-de la Lama; Villarroel; María, 2014; Chulayo; Muchenje, 2015). Contribuindo a isso, a correta rastreabilidade e recolhimento de alimentos se torna relevante, auxiliando para melhoria da gestão logística desse importante setor.

\subsection{Rastreabilidade e recolhimento de alimentos}

O sistema de rastreabilidade e recolhimento de alimentos é bastante importante para que se obtenha produtos alimentícios seguros e de qualidade gerando, assim, uma maior credibilidade e confiança dos consumidores acerca da organização, sendo de suma importância no que se refere aos componentes de controle das não conformidades e da qualidade dos sistemas de gestão (Dzwolak, 2016). Diversas pesquisas foram realizadas de forma a demonstrar a importância deste assunto para que as empresas possam manter sua confiabilidade e qualidade. Dentre elas, pode-se citar o estudo realizado por Menozzi et al. (2015) onde os autores buscaram compreender o comportamento dos consumidores de dois países europeus diferentes (Itália e França) acerca dos alimentos rastreáveis. Outro trabalho realizado nesse mesmo âmbito foi o desenvolvido por Charlebois e Haratifar (2015), onde os autores avaliaram o valor percebido de rastreabilidade alimentar na sociedade moderna pelos jovens consumidores. Além disso, através do estudo os pesquisadores constataram que a rastreabilidade dos alimentos tem sido associada a procedimentos de segurança pelos consumidores principalmente devido às inúmeras fraudes que vem ocorrendo nas indústrias alimentícias. 
Esses estudos demonstram o quão primordial é a rastreabilidade, bem como o recolhimento de alimentos para que a empresa se mantenha competitiva quanto à confiabilidade e fidelidade depositada pelo consumidor na organização. Outras pesquisas científicas foram desenvolvidas acerca dessas questões, por exemplo, um estudo voltado para medir a rastreabilidade alimentar em uma indústria do México, bem como uma análise crítica acerca da regulamentação europeia quanto à indústria alimentícia e a rastreabilidade de alimentos (Maldonado-Siman et al., 2013). Além disso, Salampasis, Tektonidis e Kalogianni, (2012) abordaram em seu estudo a descrição de uma rede semântica baseada em ontologia e orientada para serviços, que visa fornecer a infra-estrutura necessária para que a indústria de alimentos (especialmente as PME) implemente aplicativos de rastreabilidade. Por fim, um estudo onde os principais objetivos do trabalho foram identificar as necessidades em dados que são considerados como fundamental para a rastreabilidade eficiente dos alimentos (Charlier; Valceschini, 2008; Folinas; Manikas; Manos, 2006). A seguir, será discutida a importância da integração entre o produtor e o frigorífico para a análise da gestão logística.

\subsection{Gestão da cadeia de suprimentos e a integração entre o produtor e o frigorífico}

A cadeia de suprimentos é um processo complexo e, diante disso, se faz necessário que todos os seus integrantes estejam interligados de alguma forma buscando sempre o melhor para a gestão da mesma e seus processos. No que tange ao agronegócio e à gestão da cadeia de suprimentos (SCM) de um frigorífico, o entendimento de todos os processos e participantes externos é de extrema relevância, como pode ser constatado na pesquisa realizada por Tronstad e Unterschultz (2005), cujo objetivo do trabalho era examinar as estratégias de empresas da América do Norte em todos os níveis da cadeia de suprimentos, desde questões como a genética animal até o processamento e comercialização das carnes.

Segundo a pesquisa realizada por Cousineau, Lauer e Peacock (2004), quando a organização possui uma gestão logística adequada pode gerar importantes melhorias e ganhos para as operações e ainda aumentar a satisfação de seus clientes e produtores. Dessa forma, os autores sugerem que seja utilizado um programa de integração dos recursos necessários para a gestão logística da empresa. Micheli (2008) demonstrou através do tema integração entre produtor e empresa, a questão da seleção de fornecedores como forma de mitigar o risco de oferta, propondo uma nova abordagem, que é tão prática como a de custo total de propriedade e, ao mesmo tempo, um suporte real para a seleção do fornecedor como uma questão de escolha, em vez de uma restrição adicional para o tomador de decisão.

Dessa forma, possuir uma boa gestão da cadeia de suprimentos, alinhada a um relacionamento adequado aos integrantes da cadeia de suprimentos faz com que haja melhoria em todo processo 
produtivo de uma organização. Assim, autores demonstram em estudos, o forte fomento dado a este tema especifico, examinando as relações entre práticas de gerenciamento de fornecedores, contexto organizacional e desempenho do produtor, mostrando que os contextos selecionados para práticas de gerenciamento de fornecedores, sendo elas, práticas transacionais de economia e de trabalho de alto envolvimento. Estudam os fatores inerentes, que fazem das parcerias entre integrantes da cadeia de suprimentos um sucesso. Concomitante a isso, pesquisadores tem demonstrado a possibilidade de constatar que a relação empresa-fornecedor sofre de déficit de confiança mútua, gerando oportunidades de melhorias para esses relacionamentos (Valsamakis \& Groves, 1996; Wong, 2002; Chuah et al., 2010; Ambrose, Marshall, Lynch, 2010; Sharma, 2013).

Diante ao contextualizado, o presente estudo diferencia-se dos demais, contribuindo para a reflexão e propagação do tema, estreitando laços entre a indústria e seus fornecedores, demonstrando que a parceria de ambos gera resultados relevantes, propiciando o desenvolvimento não só da empresa, mas também para toda a cadeia de suprimentos. O próximo tópico demonstra a metodologia utilizada na pesquisa.

\section{Metodologia}

Para o alcance do objetivo delineado, foi empregada uma pesquisa com abordagem qualitativa e para explorar coerentemente os reais problemas utilizou-se, quanto aos objetivos, uma pesquisa exploratória, com o intento de findar as dificuldades (Gonçalves \& Meirelles, 2013). Através de uma pesquisa de campo, houve a possibilidade do levantamento de informações relevantes, tanto no que diz respeito aos responsáveis pela empresa quanto aos fornecedores de carne bovina da mesma. Foram realizadas entrevistas com o gestor do frigorífico e os produtores de gado com o intuito de identificar os gargalos na cadeia e aproximá-los, viabilizando uma maior integração.

\subsection{Escolha da empresa a ser estudada}

Diante ao mencionado, foi possível estruturar esse estudo de caso único, abrangendo parte da cadeia de suprimentos de um único frigorífico, utilizando uma coleta de dados empíricos para a análise da pesquisa. A escolha da empresa a ser pesquisada foi diante da receptividade e interesse da mesma bem como na parceria existente com um dos pesquisadores, pois o mesmo se encontra na lista de fornecedores do frigorífico, tendo contato direto com a empresa.

\subsection{Coleta dos dados}

Com o intuito de levantamento de dados relevantes, a população pesquisada dos fornecedores foi através de amostragem não probabilística por conveniência, pelo principal fato de haver poucos 
fornecedores disponíveis e que se mostraram dispostos a participar do estudo. O foco foi direcionado à análise da gestão logística bem como, a cadeia de suprimentos da carne bovina e integração da empresa com o produtor, a partir da região de principal atuação do frigorífico. Por meio das informações dadas pela empresa, os principais fornecedores concentravam-se nos municípios de São Miguel das Missões, Capão do Cipó, São Luiz Gonzaga, ljuí e Augusto Pestana, todos pertencentes à Região Sul do Brasil.

Conforme a Figura 1, a parte da cadeia analisada na presente pesquisa foi o produtor que fornece o produto e o frigorífico no qual é feito o processamento da carne, buscando atingir o objetivo delineado para o estudo.

Figura 1 - Parte analisada da cadeia logística

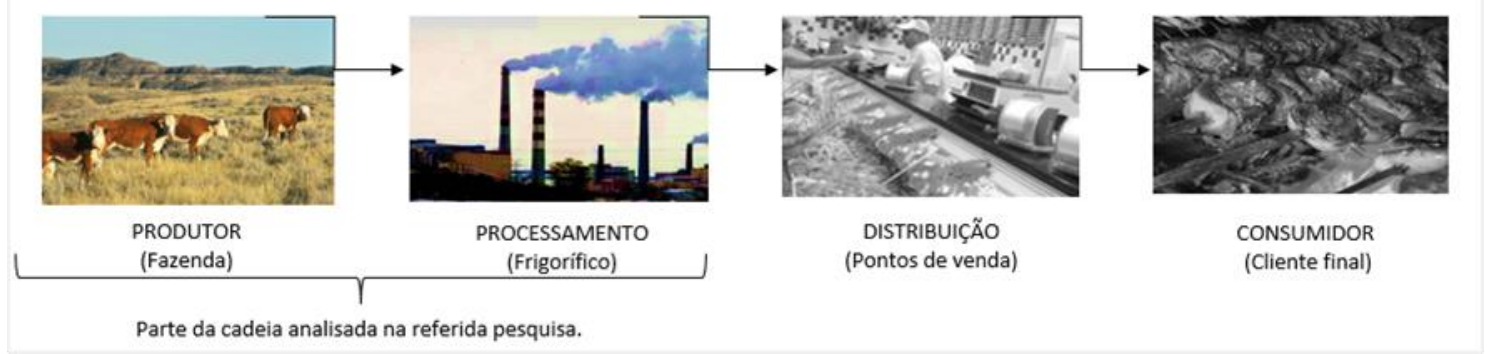

Fonte: Elaborado pelos autores.

\subsection{Entrevistas}

Foram realizadas entrevista com o gestor do frigorífico, por meio de perguntas abertas. Já as entrevistas realizadas com os produtores de gado, foram através de um questionário misto, contendo perguntas abertas e fechadas, bem como observação simples em todos os processos realizados na empresa.

\subsection{Análise dos dados}

O tratamento de dados do presente estudo foi realizado de forma quantitativa por meio de gráficos utilizando softwares, como o Excel, para os questionários de perguntas fechadas realizadas com os produtores; e de forma qualitativa para as entrevistas, perguntas abertas e observações in loco.

\section{Apresentação dos resultados}

\subsection{Descrição da empresa}

A empresa alvo da pesquisa é de pequeno porte, possuindo 58 colaboradores no seu quadro funcional. Sua capacidade de produção é de até 150 de animais abatidos (reses)/dia, sendo que a média de abates, em tempos de alta demanda, é de 75 reses por dia, e quando há baixa demanda, 45 reses 
por dia. Atualmente abrange as regiões norte e noroeste do estado do Rio Grande do Sul. A compra da matéria-prima é predominante na região noroeste e a distribuição do produto final se espalha para todo o estado.

\subsection{Avaliação da gestão de processos realizada na empresa}

Os pesquisadores buscaram avaliar como eram realizados os processos a partir do recebimento do gado no frigorífico e, dessa forma, além de identificar possíveis gargalos, caso necessário, sugerir melhorias no processo para tornar os resultados mais eficientes e consequentemente reduzir os custos.

A empresa conta com um funcionário responsável pela compra de gado, verificação da documentação original, embarque e pesagem dos animais nas propriedades de origem, sendo também responsável pelo exame sanitário através de inspeção visual, atestado de vacinação e estado nutricional. Dá-se preferência ao abate de animais jovens, ou seja, com menos de 24 meses, com bom preenchimento de polpa (coxão de dentro), e com peso vivo entre 380 a $450 \mathrm{~kg}$. O transporte dos animais é realizado por caminhão boiadeiro do tipo truque e reboque, com capacidade para até 45 animais. Após carregamento, os animais não podem estar caídos e nem mantidos apertados. Durante o transporte dos animais são realizadas paradas periódicas para revisar as condições da carga.

O descarregamento é feito de maneira humanitária, conforme exigências de bem-estar animal, evitando estresse aos mesmos, sendo este um dos principais influenciadores na qualidade da carne. Os animais chegam ao frigorífico 24 horas antes do abate e são separados nos currais por lotes. É realizada a dieta hídrica nos bovinos com o intuito de eliminar ou reduzir o conteúdo ruminar do animal, de maneira a diminuir os riscos de contaminação da carcaça por matéria fecal durante o abate.

Os animais são conduzidos dos currais por corredor até a área de aspersão, com uso de água clorada sob pressão por tempo mínimo de três minutos. Este processo auxilia na limpeza de couro e patas, para remoção das sujeiras e diminuição da carga microbiana neles existentes. Em seguida, são encaminhados ao compartimento de abate dos animais (brete), em direção ao box de atordoamento, onde possui capacidade para apenas um animal, sendo que após a entrada, a porta do tipo guilhotina deve ser fechada e sua trava de segurança checada, evitando que o animal escape ou outro entre. Neste local é realizada a insensibilização do animal que recebe um (no máximo dois) disparos de pistola pneumática de dardo cativo na região frontal do crânio, o que dilacera seu cérebro e o torna insensível a estímulos.

O abate é dividido em duas zonas, a limpa e a suja. Na zona suja são realizadas as tarefas de insensibilização, guincho, sangria, garreio de mão, serra do chifre, primeiro e segundo garreio, desprender o couro do peito e baixada do couro. Assim que concluídas as etapas anteriores, os animais passam para a zona limpa. 
Na zona limpa, os animais já estão abertos. A primeira etapa é a oclusão do esôfago, em seguida a serra de peito, evisceração, serra de meia carcaça, toalete de carcaça, dando sequência, geralmente, com o acompanhamento do fiscal da Coordenadoria de Inspeção de Produtos de Origem Animal (CISPOA) as carnes passam para carimbo, balança e classificação, após é lavada a carcaça, realizado o resfriamento desta, inspecionados e classificados os miúdos e descarna da cabeça. Ainda há a etapa de bucharia suja e limpa. Após esses processos, a carne é passada para a expedição, onde são separados os pedaços inteiros, para desossa e embalagem.

Ao longo de todo processo de produção de carne há inúmeras perdas que ocorrem pelos mais variados motivos. Buscou-se identificar quais os principais fatores que causam as perdas. Desde o carregamento na propriedade o bovino já começa a passar por situações adversas às de costume, o que causam inúmeros danos psicológicos e físicos. Os profissionais responsáveis pelo carregamento são preparados para evitar danos no processo, entretanto, alguns fatores externos acabam prejudicando diretamente a cadeia e causando grandes perdas. Um exemplo são as estradas de péssimas condições que causam estresse extremo ao bovino.

Durante o abate é possível perceber a gravidade e intensidade dos hematomas causados no manejo com os animais. A perda de carne decorrente de injeções mal aplicadas ou formas de manejo inadequadas é bastante significativa e causa inúmeros prejuízos, tanto para o frigorífico quanto para o produtor.

A partir de todas as observações, entrevistas com o gestor, a veterinária responsável pela empresa, o veterinário do Coordenadoria de Inspeção de Produtos de Origem Animal (CISPOA) e alguns colaboradores, foi possível identificar que gestão de processos ao longo da cadeia é de certa forma adequada. Há algumas falhas, principalmente quando se fala em comunicação, muitas vezes os profissionais não passam as informações completas aos seus colegas, o que acaba por prejudicar o andamento do frigorífico. Outro fator crítico na gestão é que muitas das ideias do gestor, por melhores que sejam, não são documentadas e/ou formalizadas, ou seja, ele tem boas ideias, mas não repassa aos colaboradores, perdendo oportunidades de crescimento e desenvolvimento da empresa. As decisões acerca da gestão de processos ao longo da cadeia de suprimentos se concentram nas mãos do diretorproprietário da empresa. Todas as decisões passam pelo mesmo antes de serem colocadas em prática. O frigorífico utiliza de uma gestão democrática, recebe opiniões e novas ideias dos colaboradores, entretanto, nem sempre são realmente colocadas em prática, o que, por vezes, é um desperdício, uma vez que os funcionários são quem estão diretamente ligados aos acontecimentos do dia a dia.

Outro detalhe percebido no decorrer do estudo, e muito importante, é que o controle de custos logísticos, principalmente com o transporte, que é um dos mais significativos, não é realizado de forma tão efetiva, não havendo um colaborador que realize esse controle rigorosamente e nem utilizam do sistema gerencial que a empresa possui para tal cuidado. 


\subsection{Mapeamento do processo da gestão de estoque, com o auxílio de um rastreamento desde a chegada do animal até a embalagem do produto final}

Após realizada a classificação dos cortes, os mesmos são acondicionados em suas respectivas caixas sendo, em seguida, pesados e rotulados. As caixas são lacradas com fita adesiva e transportadas através de carros/prateleira para o túnel de congelamento onde permanecerão por 48 horas. Após, são enviados para uma câmara de estocagem de resfriados.

As miudezas seguem o mesmo padrão de produção, porém, estas são embaladas individualmente com saco plástico ou plástico filme, devidamente pesadas e rotuladas e, após, encaminhadas para câmara de estocagem de resfriados.

O estoque é realizado em câmaras de estocagem, onde as temperaturas são registradas no FML 009 - Controle de Inspeção de Temperaturas de Câmaras de Resfriamento. Em caso de não conformidades nas temperaturas, imediatamente é informado ao responsável para devida correção. O estoque de resfriados tem seu ambiente sempre seco, com temperatura entre $-2 \stackrel{\circ}{ } \mathrm{C}$ a $+2{ }^{\circ} \mathrm{C}$. As caixas de embalagens são colocadas em prateleiras metálicas de acordo com o tipo de corte, identificadas através de etiquetas contendo o nome e código do produto. A primeira embalagem que entra deve ser a primeira a sair, ou seja, modelo FIFO - First In, First Out.

No estoque de congelados, as caixas com produtos embalados são empilhadas dentro da câmara de estoque devidamente afastadas das paredes para facilitar a circulação do ar frio, sendo sua temperatura constante de $-18^{\circ} \mathrm{C}$ a $-20^{\circ} \mathrm{C}$. São feitas pilhas para diferentes tipos de cortes, corretamente identificadas com o nome e código do produto, contidos na etiqueta.

O túnel de congelamento é de congelamento com duração de 24 horas e temperatura a - 35드, até a temperatura interna do produto atingir $-20^{\circ} \mathrm{C}$.

A quantidade de carne estocada é controlada por meio de um sistema onde são inseridas as quantidades de abate, o número de peças por abate e separadas de acordo com a finalidade, se para venda resfriada, congelada, desossada ou com osso. Os abates são realizados diariamente, de segunda a sexta. Em épocas onde as demandas são maiores abate-se em torno de 75 reses/dia; em épocas de baixa demanda são em torno de 45 reses/dia. Inicialmente é separado todo o estoque de pedidos in natura, os quais são entregues, geralmente, no dia seguinte, e após é realizado o processamento das peças que são vendidas desossadas e/ou embaladas a vácuo. O sistema informa a quantidade de carne que está em estoque indicando o que é in natura e embalada.

O colaborador responsável pelo estoque é o mesmo que recebe os pedidos de venda. Ele está em contato direto com os vendedores e compradores de gado. Ele tem a função de controlar o número de entradas e saídas, a disposição dos tipos de carne no container e verificar se o que está no sistema é o que há no estoque físico. 
A Resolução da Diretoria Colegiada - RDC número 24, de 08 de junho de 2015, dispõe sobre o recolhimento de alimentos e sua comunicação à Agência Nacional de Vigilância Sanitária (ANVISA) e aos consumidores.

No momento em que houve a necessidade de instalar novos equipamentos para se adaptar à normativa, em conjunto com a orientadora e a veterinária responsável pelo frigorífico, foi pensado em se utilizar do mesmo código de barras e etiqueta para identificação de lote, tipo de corte, data de abate, validade, produtor, entre outros dados, bem como auxiliar na gestão de estoques. Os benefícios da utilização do código de rastreio para auxiliar na gestão de estoque são inúmeros, dentre eles, vale destacar uma melhor gestão logística, onde os produtos produzidos anteriormente são os primeiros a sair para o mercado. Esse é um fator imprescindível para que se evitem perdas e para que o produto final saia com uma maior qualidade para o consumidor final. Além disso, a possibilidade de agregar valor com a utilização do mesmo, perante os clientes, é prevista, uma vez que o controle do produto que estão recebendo é maior, bem como a certeza de estarem vendendo uma carne de procedência confiável.

\subsection{Identificação de fatores críticos para a integração da cadeia logística existente na empresa foco de estudo, com o objetivo de diminuir as perdas decorrentes de todo o processo}

A maioria dos frigoríficos aponta a baixa qualidade das matérias-primas disponíveis pelo mercado produtor. Acredita-se que uma integração no setor poderia levar a um aumento da qualidade, redução de custos e melhorias em todo o sistema. As orientações disponibilizadas pelos frigoríficos poderiam ser melhor atendidas pelos produtores, o que levaria a uma melhora na produtividade e diminuição de perdas no processo. A partir disso, através dessa integração entre os setores seria possível entregar ao consumidor um produto de qualidade, confiável e padronizado.

Entretanto, muitos são os desafios encontrados para a integração entre produtor e frigorífico, uma vez que a diferença da forma de gestão é bastante significativa. Os principais fatores críticos identificados no decorrer da pesquisa, os quais são vilões no momento de integração, são a falta de comunicação entre setor primário e indústria, a falta de credibilidade de um para o outro, pouca confiança entre os setores, falta de um contrato para que garanta os direitos e deveres de cada agente.

Analisando os fatores críticos e na tentativa de identificar a possibilidade de integração logística entre o frigorífico e seus fornecedores, foram aplicados alguns questionários nos 10 produtores de gado de corte indicados pela empresa. Através da aplicação dos mesmos, pode-se perceber que 5 desses fornecedores são de faixa etária entre 61 e 75 anos, 4 de 46 a 60 anos e 1 de 30 a 45 anos, fechando assim os fornecedores pesquisados. Conforme mencionado, os pesquisados foram indicados pelo frigorífico como sendo os mais representativos, sendo que $10 \%$ deles residem em Augusto Pestana, 10\% encontram-se no município de ljuí, 20\% em São Luiz Gonzaga e nos municípios de Capão do Cipó e São 
Miguel das Missões, distribuem-se 30\% em cada um desses. Na Figura 2, a média do número de reses dos produtores pesquisados é apresentada. Apenas um dos questionados possui mais de 4000 reses e apenas um entre 100 e 500, dois produtores possuem entre 2501 e 4000 reses, três pesquisados entre 1001 e 2500 cabeças de gado e três entre 501 e 1000 reses. Todos os pesquisados fazem a cria e recria na propriedade.

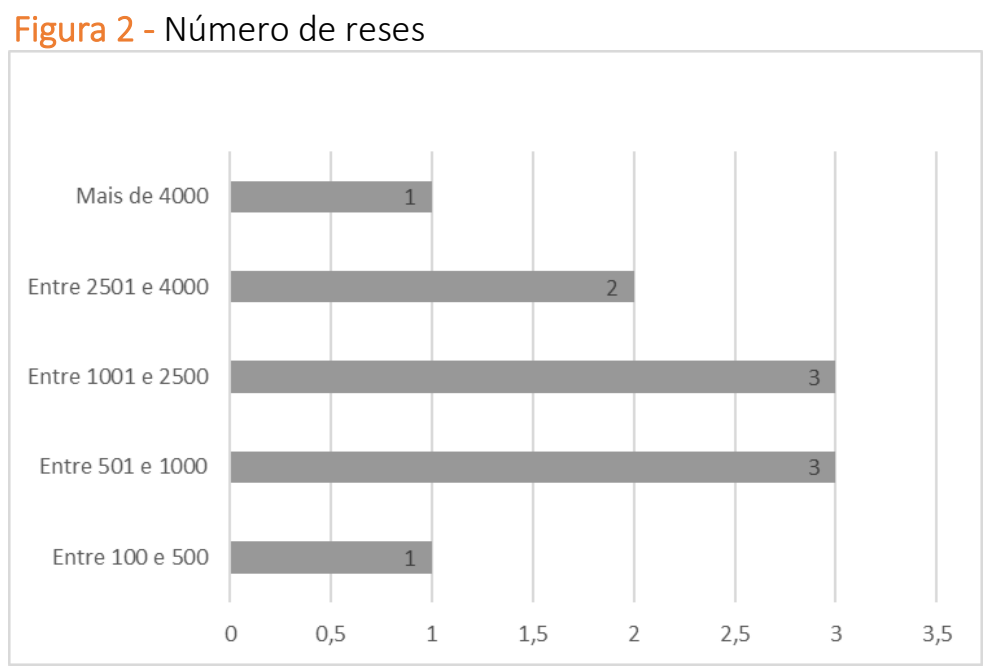

Fonte: Dados da pesquisa.

Nas visitas realizadas ao frigorifico, observou-se a grande preferência por raças britânicas, onde os principais fornecedores criam essas raças. A grande maioria possui a reses da raça Braford sendo 50\% dos pesquisados, 30\% optam por Angus, 20\% pela raça Devon.

Quanto aos caminhões utilizados para a busca da matéria-prima nas propriedades, como demonstrado na Figura 3, encontra-se em bom estado de conservação segundo a maioria dos respondentes e ainda dois dos pesquisados, consideram em ótimo estado.

Figura 3 - Situação dos caminhões que realizam o transporte dos bovinos até o frigorífico

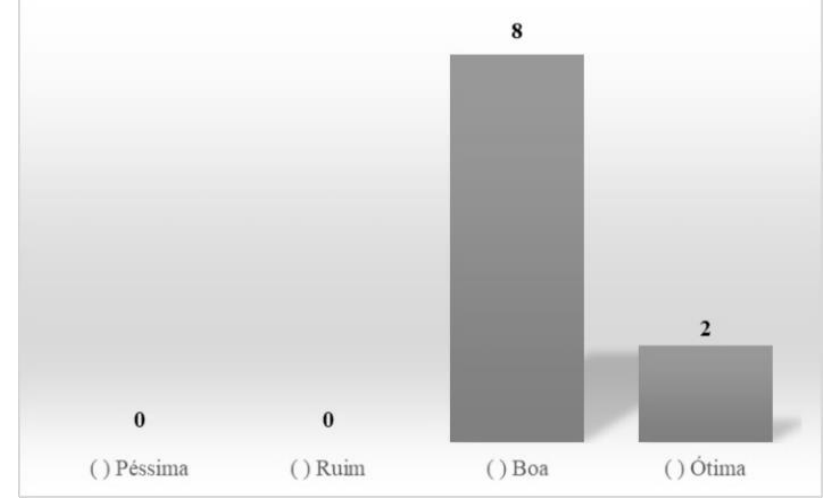

Fonte: Dados da pesquisa. 
A Figura 4 se refere aos funcionários que realizam o carregamento do gado na propriedade rural. De acordo com os pesquisados, a maioria os considera com boa preparação. Apenas um deles considera com uma ótima preparação, bem como, apenas um respondente os considera com uma preparação ruim para tal função. Esse dado é muito importante, uma vez que no carregamento podem ocorrer inúmeras avarias, e acabar em grandes perdas, tanto para o frigorífico quanto para o produtor.

Figura 4 - Preparação dos funcionários responsáveis pelo carregamento na propriedade

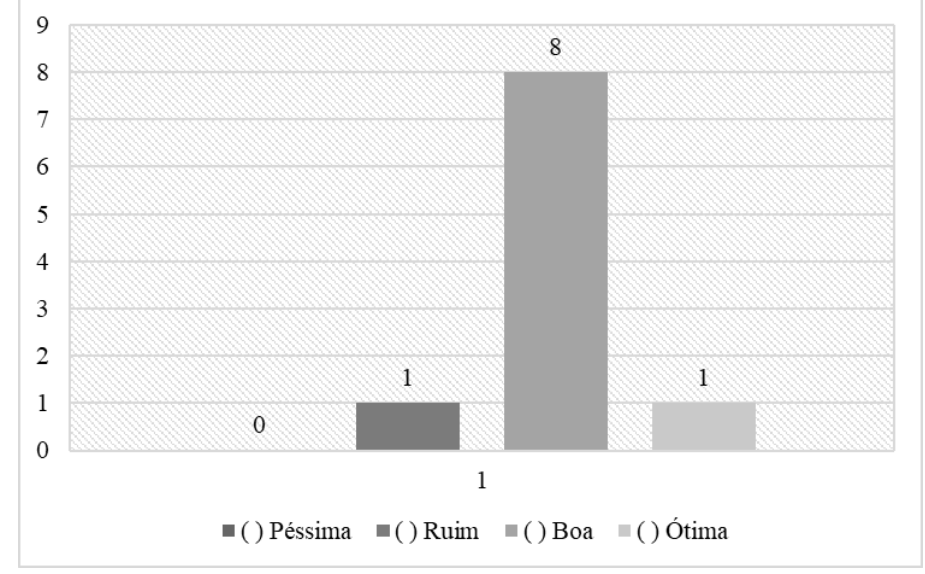

Fonte: Dados da pesquisa.

Um dos questionamentos aos produtores era sobre as perdas que ocorrem no decorrer de todo o processo logístico do bovino de corte. De acordo com os mesmos, quatro deles dizem que consideram o transporte até o frigorífico o principal causador de danos, principalmente pelas péssimas condições das estradas da região. Outros quatro pesquisados disseram que na própria propriedade é causada a maioria das perdas, principalmente pelo fato de os funcionários não possuírem qualificação na hora de manejar o gado, bem como no momento de aplicar as vacinas, o que é considerado por esses produtores um dos principais fatores de perda de carne.

A pergunta seguinte era se o frigorífico já havia realizado algum treinamento ou explicação para seus fornecedores de como devem ser aplicadas as vacinas e como devem proceder com o manejo dos animais. Observou-se, que 70\% dos entrevistados dizem nunca terem recebido algum tipo de instrução. Apenas 30\% disseram já ter recebido orientações pertinentes à vacina e manejo. Esses dizem que o próprio comprador, o qual geralmente acompanha o carregamento, instrui tanto os produtores quanto os funcionários. Outros pesquisados disseram ter recebido instruções no frigorífico, quando assistiram a um abate e observaram como há perdas por abcessos e manejo inadequado.

Outro questionamento aos produtores era sobre a presença de um veterinário ou técnico responsável pelas vacinações que são feitas no decorrer da criação. Como já comentado pelo gestor do frigorífico, há uma minoria de produtores que contratam veterinários em sua propriedade. Das propriedades pesquisadas, apenas uma possui a presença desse profissional diariamente. Ainda 
comentou ao responder à questão que só contratou por ter um número grande de reses pois, chamar sempre que havia necessidade estava se tornando inviável. Tal produtor, é o único, que possui mais de 4000 reses em sua propriedade. Os demais pesquisados, afirmaram não possuir nenhum veterinário ou técnico agropecuário trabalhando na fazenda diariamente.

Quando questionados se possuíam algum curso para aplicação de vacinas e manejo com os bovinos, $60 \%$ dos respondentes afirmam possuir, pois a maioria recebe instruções na empresa onde compram os insumos, afirmando que a mesma oferta esses tipos de treinamentos periodicamente. Os outros $40 \%$ dos produtores disseram não possuir nenhum tipo de treinamento e que fazem como aprenderam, na prática do dia a dia.

Foi perguntado aos produtores se os mesmos utilizam alguns procedimentos ou cuidados ao vacinar os bovinos, bem como ao manejá-los. Todos os participantes responderam que sim. A maioria deles diz tomar cuidado principalmente com a roupa que utiliza ao lidar com os animais e que não podem utilizar roupas de cores muito vivas, principalmente vermelha. Os animais ficam nervosos, o que acaba por prejudicar todo o andamento das atividades. Também falam sobre como tocar o gado, que devem cuidar muito com os barulhos e objetos a serem utilizados, nenhum tipo de pontiagudo ou galhos, apenas bolsas ou chocalhos. Reforçam o cuidado que deve haver com a vacinação para que seja realizada no local correto tentando evitar não seria abscessos. Um dos produtores ainda comentou que na sua propriedade apenas ele aplica vacinas, pois os funcionários nem sempre fazem corretamente, o que acaba prejudicando o animal.

Quando questionados sobre a possibilidade de integração, 90\% dos respondentes dizem haver essa possibilidade, e apenas um respondeu negativamente à pergunta, justificando que o frigorífico pode fazer exigências demasiadas, as quais se tornem inviáveis de se realizar e acabe com a parceria entre o pequeno produtor e o frigorífico.

Quando perguntado ao gestor do frigorífico se havia uma preferência por raça, o mesmo respondeu que optam, sempre que a oferta é suficiente, por raças britânicas. Perguntou-se aos produtores se a empresa, alguma vez, os informou dessa preferência. Oito deles disseram que sim, que o frigorífico os comunicou da preferência por raças britânicas, e de antemão comentaram que é a preferência da maioria dos frigoríficos. Apenas dois disseram não terem sido avisados por essa preferência, mas mesmo assim criam apenas raças britânicas.

Os resultados obtidos com o questionamento de haver algum contrato ou documento entre o mesmo e o frigorífico para o fornecimento de gado bovino de corte mostraram que $100 \%$ dos respondentes disseram não haver nenhum tipo de contrato entre os agentes. (se for esta, reformular a frase sem o ponto final no meio dela)

Outro questionamento aos produtores era se na opinião deles, caso houvesse o firmamento de um contrato de fornecimento com o frigorífico, seria possível atender às exigências de qualidade e como 
eles acreditam que isso poderia ocorrer. A grande maioria concorda que o estabelecimento de um contrato poderia aumentar a possibilidade de atender às exigências, uma vez que manteriam uma parceria tendo a garantia de venda. Alguns citam que ficam apreensivos em atender algumas especificações sem ter segurança de que depois continuarão vendendo à mesma empresa, dificultando, muitas vezes, os negócios com outros frigoríficos pois, às vezes, há mudança de premissas de um para outro.

Acredita-se que possa haver possibilidade de desenvolver uma integração maior entre produtor e indústria, visto que a principal reclamação por parte dos frigoríficos é a falta de regularidade da oferta de matéria-prima de qualidade. Diante disso, através de uma negociação e parceria firmada com os produtores, os mesmos deverão obrigatoriamente manter os seus contratos e cumprir conforme as exigências dos frigoríficos.

\subsection{Apresentação de propostas com o foco de melhorar a gestão logística da empresa pesquisada, visando um aumento da sua eficiência operacional}

A partir das análises realizadas, um dos primeiros pontos observados foi a gestão dos processos realizados na empresa atualmente, bem como a relação da mesma (frigorífico) com os produtores. Observou-se que a gestão em grande parte é feita corretamente, e são realizadas todas as premissas cabíveis para que haja eficiência nos processos realizados, bem como há um alto controle dos mesmos, o que evidencia a qualidade dos produtos oferecidos pela empresa. Ademais, apesar de a gestão estar correta, cabe ressaltar que no decorrer de toda a cadeia verificou-se que existem perdas em todos os processos como, por exemplo, desperdício de matéria-prima e falhas de comunicação entre os setores da empresa.

Desse modo, o Quadro 1 apresenta as propostas de melhoria a partir dos dados e análises realizadas, explicitando as propostas cabíveis para a solução dos gargalos encontrados. 
Quadro 1 - Propostas de melhoria a partir dos dados coletados e analisados

Fonte dos dados

Fator crítico

Fator crítico

\begin{tabular}{|l|l|}
\hline Fator crítico & período regular \\
\hline Pesquisa & Redução das perd \\
\hline & $\begin{array}{l}\text { Integração com } \\
\text { fornecedor }\end{array}$ \\
\hline
\end{tabular}

Entrevista

Identificar como é realizada a gestão logística

Entrevista/Observação in loco

Mapear a gestão de estoques
Proposta

Parceria com o produtor

Contrato de

fornecimento

Técnico para instrução de vacinação e manejo

Elaboração de contrato, contendo normas para ambos os agentes

Utilizar o ERP que a empresa já possui para controle de custos de transportes

Utilizar o código de rastreabilidade para auxiliar na gestão de estoques
Resultado

Aumento da qualidade.

Atender a demanda do

cliente final, nos

períodos de pico de venda.

Redução nas perdas por

hematomas e abcessos de vacina.

Fidelização do

fornecedor, aumento da

qualidade, diminuição

de perdas e

fornecimento regular de matéria prima.

Reduzir os gargalos

existentes,

principalmente, no transporte.

Abolir com as perdas

causadas por

vencimento em

produtos congelados.

Fonte: Elaborado pelos autores.

Conforme pode ser visualizado no Quadro 1, sugeriu-se que seja realizado maior controle nos custos logísticos por meio da empresa, uma vez que já possuem essa função no sistema e podem reduzir os gastos no momento em que começarem a fazer o uso da ferramenta para agregar ao controle. Os custos de transporte podem chegar a 70\% do total dos custos logísticos e, sabendo-se que o frigorífico além de fazer a distribuição de seus produtos ainda fazem a busca de seu suprimento, essa proporção pode aumentar.

Verificou-se a importância de uma boa comunicação na linha gestor - funcionários, já que os controles são bem aplicados e o manual de boas práticas de fabricação estão bem claros, havendo uma boa comunicação entre esses, poderá fazer com que os processos sejam ainda mais eficientes e os resultados otimizados. Desta maneira, sugere-se que haja maior participação dos funcionários, reuniões periódicas, com o intuito de se avaliar as ideias dos colaboradores e ajustar as mesmas para colocá-las em prática.

Foi proposto ao gestor que explore mais o seu sistema de informações gerenciais para que todos tenham acesso às decisões e possam auxiliar nas mesmas. Adicionalmente, que relatórios para as tomadas de decisões sejam mais utilizados, bem como do auxílio dos colaboradores da produção, que são quem estão no chão de fábrica e sabem o que realmente acontece no dia a dia. Receber ideias dos colaboradores pode auxiliar o gestor na tomada de decisões. Os funcionários estão diretamente ligados à produção e são os primeiros a perceberem quando há alterações no andamento da produção, tendo 
a possibilidade de expor suas ideias e as percepções do que ocorre no andamento da indústria, a gestão pode ganhar em agilidade na tomada de decisões.

Na chegada das reses na empresa se identificam inúmeros danos, hematomas, algumas com cortes e sinais de machucados profundos. Para tal foi desenvolvido um check list de recebimento dos bovinos, verificando todos os pontos relevantes da estrutura do frigorífico para o recebimento, bem como do caminhão que realizou o transporte e normas que devem ser seguidas para o início do abate.

A gestão da parceria com fornecedor poderia ser realizada pelo frigorífico por possuir maiores condições de informatização e estrutura administrativa. Para vir a desenvolver essa forma de gestão, o ideal é aprofundar ainda mais os estudos, verificando todos os agentes, e principalmente pesquisar um número maior de produtores. Entretanto, pode-se dizer que com o desenvolvimento dessa integração ambos melhorariam seus resultados e reduziriam as perdas que ocorrem em todos os elos dessa cadeia.

\section{Considerações finais}

Com o intuito de auxiliar na melhoria da gestão do negócio familiar, bem como colaborar com a disseminação de conhecimentos acerca dos temas gestão logística e gestão da cadeia de suprimentos, o presente estudo objetivou investigar a integração entre frigorífico e fornecedor, além de realizar uma análise da gestão logística, identificando os gargalos existentes e apresentando sugestões de melhorias.

O desenvolvimento do presente estudo possibilitou uma análise de toda a gestão da cadeia logística da carne bovina, iniciando na análise no setor primário da cadeia, no produtor rural e prosseguindo com a mesma até a saída do produto final para a venda ao consumidor. Afirma-se que foi realizada a observação de todos os processos envolvidos, sendo possível identificar os pontos críticos de perdas e as possíveis melhorias, tendo como norteamento a redução de perdas, conforme elucidado no decorrer do estudo. Cabe ressaltar a importância exercida pela cadeia logística bem como a forte ligação de cada setor, podendo serem estes fatores chave para o sucesso ou fracasso de uma organização. Ainda, pode-se comparar os processos a uma engrenagem, onde no momento em que um parar ou tiver qualquer problema para o seu desenvolvimento, todos os restantes passam por atrasos e perdas. Sendo assim, para que o fluxo da gestão logística do bovino de corte tenha um bom desempenho, todos os elos devem estar ligados aos mesmos interesses e procurando o rendimento máximo. No que tange ao alcance, as prerrogativas exigidas pelo consumidor final, todos os agentes devem estar alinhados, partindo da premissa que as organizações devem satisfazer as necessidades e demandas dos clientes. E por esse motivo se dá a grande importância de uma gestão integrada entre todos os elos.

Apesar de haver possibilidade de integração, mesmo que com pouca informatização, observouse no decorrer do estudo a dificuldade de aproximação entre produtor e indústria, em função, 
principalmente, da falta de confiança existente entre os elos. Finalmente, se mostra de grande valia a tentativa de integrar o frigorífico ao produtor, mesmo com as dificuldades que possam surgir. Se conseguido tal feito, esses agentes ganharão muitos benefícios e otimizarão os resultados obtidos.

Para se pôr em uso todas as proposições e, principalmente, a integração, se necessita de alguns estudos mais aprofundados, e obviamente que isso demanda de alguns custos e tempo. Porém, de antemão, pode-se dizer que vale a pena a tentativa, pois cada atitude levará à redução de custos para a empresa e fornecedores. É possível afirmar que a presente pesquisa é de suma relevância tanto para as organizações quanto para a academiaAo se-identificar os fatores que prejudicam a organização estudada, é possível auxiliar empresas que passam por problemas semelhantes, fornecendo subsídios e denotando a importância de uma gestão logística alinhada e em perfeita harmonia.

Como sugestão de estudos futuros, indica-se a utilização do método Fuzzy TOPSIS para avaliação dos fornecedores, alinhando os mesmos a sustentabilidade, com o intuito de auxiliar a empresa na decisão final. Ainda, indica-se a utilização do método Fuzzy AHP para priorização dos fatores mais críticos de perdas e gargalos na produção, com a finalidade de mitigar tais problemas.

\section{Referências}

Brasil. Decreto no 30.691, de 29 de março de 1952. Aprova o novo regulamento da Inspeção Industrial e Sanitária de Produtos de Origem Animal. Diário Oficial. Brasília, DF. 29 mar. 1952. Disponível em: <https://www.planalto.gov.br/ccivil_03/decreto/1950-1969/D30691.htm>. Acesso em: 17 out. 2016.

Ambrose, E., Marshall, D., \& Lynch, D. (2010). Buyer supplier perspectives on supply chain relationships. International Journal of Operations \& Production Management, 30(12), 1269-1290. https://doi.org/10.1108/01443571011094262.

Bonamigo, A., \& Rodriguez, C. M. T. (2017). The concept Hoshin Kanri applied in supply chain management. Journal of Lean Systems, 2(3), 107-118.

Bowersox, Donald J, et al. (2014) Gestão Logística da Cadeia de Suprimentos. 4. ed. Porto Alegre: Bookman.

Charlebois, S., \& Haratifar, S. (2015). The perceived value of dairy product traceability in modern society: An exploratory study. Journal of dairy science, 98(5), 3514-3525. https://doi.org/10.3168/jds.2014-9247.

Charlier, C., \& Valceschini, E. (2008). Coordination for traceability in the food chain. A critical appraisal of European regulation. European Journal of Law and Economics, 25(1), 1-15. https://doi.org/10.1007/s10657-007-9038-2.

Chuah, P., Peng Wong, W., Ramayah, T., \& Jantan, M. (2010). Organizational context, supplier management practices and supplier performance: A case study of a multinational company in Malaysia. Journal of Enterprise Information Management, 23(6), 724-758. https://doi.org/10.1108/17410391011088619. 
Chulayo, A. Y., \& Muchenje, V. (2015). A balanced perspective on animal welfare for improved meat and meat products. South African Journal of Animal Science, 45(5), 452-469.

http://dx.doi.org/10.4314/sajas.v45i5.2.

Corrêa, H. L. (2014). Administração de cadeias de suprimento e logística. Editora Atlas SA.

COUNCIL OF SUPPLY CHAIN MANAGEMENT PROFESSIONALS. CSCMP Supply Chain Management. 2013. Extraído em 12 de setembro de 2019, de http://www.clm1.org/aboutus/supply-chainmanagement-definitions.

Cousineau, M., Lauer, T. W., \& Peacock, E. (2004). Supplier source integration in a large manufacturing company. Supply chain management: an international journal, 9(1), 110-117.

https://doi.org/10.1108/13598540410517629.

Diskin, M. G., \& Kenny, D. A. (2016). Managing the reproductive performance of beef cows. Theriogenology, 86(1), 379-387. https://doi.org/10.1016/j.theriogenology.2016.04.052.

Dzwolak, W. (2016). Practical aspects of traceability in small food businesses with implemented food safety management systems. Journal of food safety, 36(2), 203-213. https://doi.org/10.1111/jfs.12232.

Folinas, D., Manikas, I., \& Manos, B. (2006). Traceability data management for food chains. British Food Journal, 108(8), 622-633. https://doi.org/10.1108/00070700610682319.

FOOD AND AGRICULTURE ORGANIZATION OF THE UNITED NATIONS (FAO). FAO's role in livestock and the environment. FAO, 2017. Disponível em: <http://www.fao.org/livestock-environment/en/>. Acessado em: 23 dez de 2017.

FORMIGONI, Ivan. Qual é o consumo da carne bovina no pais? FarmNews. 2017. Disponivel em: $<$ http://www.farmnews.com.br/pesquisa-e-desenvolvimento/consumo-de-carne-bovina-4/>. Acessado em: 27 dez de 2017.

Groves, G., \& Valsamakis, V. (1998). Supplier-customer relationships and company performance. The International Journal of Logistics Management, 9(2), 51-64. https://doi.org/10.1108/09574099810805834.

Holweg, M. (2005). An investigation into supplier responsiveness: Empirical evidence from the automotive Industry. The International Journal of Logistics Management, 16(1), 96-119. https://doi.org/10.1108/09574090510617376.

Jordan, G., Thomasius, R., Schröder, H., Wulf, J. S., Schlüter, O., Sumpf, B., \& Schwägele, F. (2009). Non-invasive mobile monitoring of meat quality. Journal für Verbraucherschutz und Lebensmittelsicherheit, 4(1), 7-14. https://doi.org/10.1007/s00003-009-0389-1.

Knoll, S., Marques, C. S. S., Liu, J., Zhong, F., Padula, A. D., \& Jardim Barcellos, J. O. (2017). The SinoBrazilian beef supply chain: mapping and risk detection. British Food Journal, 119(1), 164-180. https://doi.org/10.1108/BFJ-07-2016-0346.

Maldonado-Siman, E. M. A. Godinez-Gonzalez, C. S., Cadena-Meneses, J. A., Ruíz-Flores, Agustín., \& Aranda-Osorio, Gilberto (2013). Traceability in the mexican dairy processing industry. Journal of Food Processing and Preservation, 37(5), 399-404. https://doi.org/10.1111/j.1745-

4549.2011.00663.x. 
Menozzi, D., Halawany-Darson, R., Mora, C., \& Giraud, G. (2015). Motives towards traceable food choice: A comparison between French and Italian consumers. Food Control, 49, 40-48. https://doi.org/10.1016/j.foodcont.2013.09.006.

Micheli, G. J. (2008). A decision-maker-centred supplier selection approach for critical supplies. Management Decision, 46(6), 918-932. https://doi.org/10.1108/00251740810882671.

Miranda-De La Lama, G. C. et al. (2010). Critical points in the pre-slaughter logistic chain of lambs in Spain that may compromise the animal's welfare. Small Ruminant Research, 90(1), 174178. https://doi.org/10.1016/j.smallrumres.2010.02.011.

Miranda-De La Lama, G. C., Villarroel, M., \& María, G. A. (2014). Livestock transport from the perspective of the pre-slaughter logistic chain: a review. Meat Science, 98(1), 9-20. https://doi.org/10.1016/j.meatsci.2014.04.005.

Salampasis, M., Tektonidis, D., \& Kalogianni, E. P. (2012). TraceALL: a semantic web framework for food traceability systems. Journal of Systems and Information Technology, 14(4), 302-317. https://doi.org/10.1108/13287261211279053.

Sharma, V. M. (2013). Enhancement of trust in the export management company-supplier relationship through e-business. International Journal of Commerce and Management, 23(1), 24-37. https://doi.org/10.1108/10569211311311131.

Soysal, M., Bloemhof-Ruwaard, J. M., \& Van der Vorst, J. G. A. J. (2014). Modelling food logistics networks with emission considerations: The case of an international beef supply chain. International Journal of Production Economics, 152, 57-70. https://doi.org/10.1016/j.ijpe.2013.12.012.

Tronstad, R., \& Unterschultz, J. (2005). Looking beyond value-based pricing of beef in North America. Supply Chain Management: An International Journal, 10(3), 214-222. https://doi.org/10.1108/13598540510606278.

Valsamakis, V., \& Groves, G. (1996). Supplier-customer relationships: do partnerships perform better?. Journal of Fashion Marketing and Management: An International Journal, 1(1), 9-25. https://doi.org/10.1108/eb022487.

Wong, A. (2002). Sustaining company performance through partnering with suppliers. International Journal of Quality \& Reliability Management, 19(5), 567-580. https://doi.org/10.1108/02656710210427539. 